\title{
The "mental feature" in mental illness: difficulties that this reality poses for diagnosis and classification
}

\author{
O "mental" na doença mental: dificuldades que sua realidade \\ impõe em relação a diagnóstico e classificação
}

Humberto L. Casarotti*

\begin{abstract}
Four points are considered in this article. In the first place, it is argued that the "settings" of psychiatric care express the need to respond to the degree of decrease in personal freedom of the patient. Then, the issue of how "the mental feature" of the mental pathology has been recognized and categorized since the 18th century is examined, pointing out the difficulties involved in considering the mental nature of the subject of psychiatry. In the third place, the issue of how current systems of diagnosis and classification are posed regarding this reality is briefly looked at. Finally, the characteristics of a working hypothesis that allows organizing consistent clinical facts providing a heuristic perspective are analyzed.
\end{abstract}

Keywords: Psychiatric care, problems in diagnosis and classification, organic-dynamic hypothesis.

\begin{abstract}
Resumo
Neste artigo, quatro pontos são considerados. Em primeiro lugar, argumenta-se que os "espaços" da atenção psiquiátrica expressam a necessidade de responder ao grau de diminuição da liberdade pessoal do paciente. Em seguida, são discutidas as formas como o "mental" da doença mental tem sido reconhecido e categorizado a partir do século 18 , apontando para dificuldades envolvidas ao se considerar o caráter mental do objeto da psiquiatria. Em terceiro lugar, são discutidas brevemente as formas como os sistemas atuais de diagnóstico e classificação se posicionam sobre essa realidade. Finalmente, as características de uma hipótese de trabalho que permita organizar de modo coerente os fatos clínicos e que proporcione uma perspectiva que seja heurística são analisadas.
\end{abstract}

Descritores: Atenção psiquiátrica, problemas de diagnóstico e classificação, hipótese orgânico-dinâmica.

\footnotetext{
* Psychiatrist, neurologist, coroner. Translator of Henry Ey's work into Spanish. Financial support: none.

No conflicts of interest declared concerning the publication of this article.

Suggested citation: Casarotti HL. The "mental feature" in mental illness: difficulties that this reality poses for diagnosis and classification. Trends Psychiatry Psychother. 2013;35(2):87-98.
} 


\section{Introduction}

Psychiatry, as pointed out by Henry $\mathrm{Ey}^{1}{ }^{1}$ is the response from physicians to the need of giving "special" care to mentally-ill patients in order to cure "their psychic illnesses." "Special" treatments and care settings are based on the fact that these illnesses are neither entirely psychic nor organic in a vegetative way.

Which is the subject of this "special medicine," different from other medical specialties such as cardiology, pneumology, endocrinology? Its subject are the disorganizations of psychism determined by disorders in nervous system integration (somatosis), or, in other words, which puts into evidence the immaturity or the disorganization of psychic functions in inter-human relationships. As it will be observed throughout the present paper, this "mental" subject, which has determined the progressive organization of the health care psychiatric system, poses several difficulties regarding the diagnosis and the classification of mental illnesses.

This article may be supplemented with the reading of some of the many existing studies on diagnosis and classification in psychiatry, published before ${ }^{2-4}$ and after $^{5-7}$ the introduction of the DSM-III.

\section{Settings of psychiatric care}

The tacit or explicit recognition that "the mental feature" of mental illnesses is what, beyond hypotheses and discussions on its reality and nature, has determined the fact that the care for this pathology is provided by similar care systems in different countries. Care services that, although being carried out at physical settings similar to those used in the care for patients with vegetative diseases (cardiorespiratory, digestive, etc.): doctor's office, emergency room and hospital, are different because the specific "settings" of psychiatric care are "settings" with a primarily relational, and not spatial, nature.

Psychiatrists should make two types of decision concerning those who consult them. On one hand, just like physicians from the other medical fields, they should decide the therapeutic plan, which depends on the type de psychopathological structure, the evolutionary phase, and the causative process of the morbidity. However, on the other hand, psychiatrists should decide in which care setting this care can and should be provided, "settings" that are determined not primarily by diagnosis but by the degree of freedom the patient has lost or, -put it another way- by the degree of autonomy he or she still has. $\mathrm{H}$. Ey referred to the psychiatric pathology as a "pathology of freedom," and W. Blankenburg ${ }^{8}$ named the degree of preserved freedom as the "other" diagnosis. This is the degree of freedom that enables the type of relationship psychiatrist and patient can establish.

This "other" diagnosis, which determines the care settings and represents the more global mental aspect characterizing psychiatric patients and their evaluation, is more an intuitive act rather than a reflexive one, because personal freedom, just like rationality, emerges directly from the contact with others.

Psychiatric patients, grouped according to their degree of autonomy, i.e., considered from the point of view of this "other" diagnosis, are distributed into 4 care "settings," according to the somatic or psychological treatment required in the evolutionary stage patients are in.

a) When their autonomy is similar to that of a nonmentally ill person ("other conditions that may be a focus of clinical attention": V codes of DSM and Z codes of ICD, character disorders, "neurotic patients with or without symptoms," etc.) and the goal is that the patient functions better than before, the relationship established is similar to that maintained by two adults who freely agree on what to do. The "setting" in which this goal may be achieved is that of the doctor's office.

b) When the decrease in personal autonomy that determines the illness process negatively biases patient's decisions regarding his or her well-being (schizophrenias of slow evolution, bipolar disorders; character disorders; alcoholic and drug-addictions; dementias, etc.), the relationship established has the non-paternalistic parental style that an adult maintains with an adolescent child, aiming to prevent the increase in functional impairment. This relationship, which introduces different nuances to the psychiatrist-patient relationship in comparison to the previous group, can develop in several "settings" (doctor's office with family follow-up, day hospitals, therapeutic communities, drug control services, etc.).

c) In cases in which the reduction in autonomy represents a state of transient disability (acute psychotic episodes, severe anxiety crises, several chronic psychotic decompensations, alcohol and drug detoxification, etc.), the psychiatrist-patient relationship that can be established requires the psychiatrist, in order to solve the disorder as soon as possible, to work with emergency or hospitalization services the same way an adult works with someone temporarily disabled.

d) Finally, with impaired patients in whom the autonomy is minimal or almost non-existent (severe oligophrenias, chronic psychosis with long-term evolution, severe character disorders, etc.), the psychiatrist-patient relationship is that one has with severely disabled people. Consequently, it is necessary 
to provide protected accommodation, appropriate nutrition, solution to medical emergencies, etc. These "custodial" goals, which traditionally were achieved by putting patients into an institution ("involuntary civil commitment"* or institutionalization), currently tend to be achieved, according to socioeconomic possibilities, through other protective "custodial" means.

The fact that the psychiatric care system is similar in different countries seems to be contradictory to the fact that technicians working in this field have different hypotheses. However, this contradiction disappears when one considers not the hypotheses with which different technicians work but what they do regarding their patients. And what they do with their patients, when they behave responsibly, is basically related to the "other" diagnosis," which depends on the type of illness, the evolutionary moment, ${ }^{+*}$ as well as on several circumstantial factors.

Let us see now how this psychic reality of mental illnesses, which in fact formats the psychiatric care system, has been recognized and what difficulties this reality poses regarding diagnosis and classification.

\section{Evolution of psychiatry regarding diagnosis and classification}

\section{"The mental feature" of the acute mental illness understood as a vegetative symptom}

Mental illnesses were initially identified in their acute forms. The sudden onset of mental changes that characterizes these forms could not go unnoticed, both due to its qualitative difference from normal psychic experiences and to its relationship with evident pathological processes. The pathological mental changes recognized by medicine since the beginning of its history were another chapter of the pathology of the organs of vegetative life (pulmonary, cardiac, digestive, etc.), i.e., they were not recognized as having a mental specificity. In order to understand the meaning of this statement, one should consider the birth of medicine.

Medicine was born with Hippocrates in the 5th century $B C$, when it was found that patients' complaints were the expression of a bodily disorder. ${ }^{9}$ Patient's complaints are no longer considered an out-of-body phenomenon and begin to be understood as an in-body phenomenon, "in its organization." Physiologists (the philosophers of the "physis") found that illnesses were natural rather than supernatural phenomena and that they were "disorganizations in the organization of the body," of the "organism." Its disorganization reveals its construction order and so the pre-technical medicine (that of the shamans) turned into a technical knowledge ("iatrike tekhne"). Since then, this finding of the existence of a bodily disorder (subject of the diagnosis of the organic process or "somatosis") in and thorough clinical manifestations (subject of the semiological diagnosis) represented the scheme applied to all pathologies (Figure 1). This scheme presents realities of different

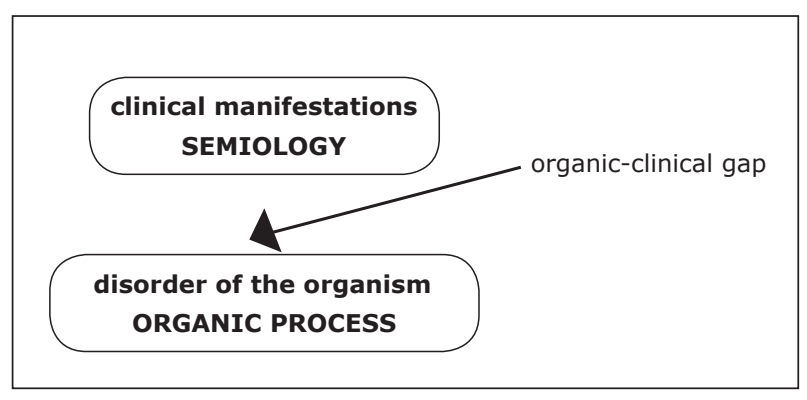

Figure 1 - Scheme representing pathologies

\footnotetext{
${ }^{*}$ In mental disease care, it is convenient to differentiate the relational structure of the hospital setting to that of the custodial setting, referring, in the first case, to "hospitalization", and in the second, to "involuntary civil commitment" or "institutionalization". The use of both terms makes reference, on one hand, to the existence of different healthcare contexts and, on the other hand, to the fact that both "settings" are not physical locations but two types of psychiatrist-patient relationship (which can take place in different formats according to socioeconomic conditions).

${ }^{+}$Psychiatrists who work with psychotherapy at a doctor's office may think of the cause of the morbidity according to an exclusively "psychogenetic" hypothesis, but if, at a given moment, their patient becomes severely depressed and threatens to commit suicide, they, being responsible for their patient, will refer him or her to a psychiatrist who works at a hospital setting. In turn, this other technician, who works with an "organogenetic" hypothesis, may treat the patient at the hospital without taking into special account to the biographical aspects of the patient, which will have a practical meaning again when the patient improves from his or her acute depressive state and resumes psychotherapy. The same happens to a psychiatrist who treats schizophrenic patients and, in certain cases and on certain occasions, in order to treat them, should incorporate their family into the psychiatrist-patient relationship. This "change of relational setting" essentially modifies aspects related to written agreement, confidentiality, and voluntary treatment. What is important to point out here is that, with their behavior, technicians provide evidence that, beyond hypotheses, their patients need several "care settings", according to the evolutionary phase of their condition.

* The organization of the psychiatric field in care and teaching activities requires taking into account the different care settings. Since patients need these settings according to the type of mental disease they suffer from, and especially according to their evolutionary phase, the organization of teaching activities, as well as the adoption of administrative decisions regarding the structure of the care system, requires knowledge on the different patients who need these different settings. Behaving differently means, on one hand, limiting learning to a single part of mental pathology (to chronic patients or to acute patients), and, on the other, risking the organization of the health care system according to a single part of psychiatric disease, i.e., by considering partial hypotheses as the organizational criteria.
} 
nature, among which there is an "organic-clinical gap" ("écart organo-clinique") that can be covered from two directions: either in the direction taken by clinicians in their semiological work, in which they find the somatosis based on symptoms, or like pathologists do, from somatosis to manifestations.

This scheme enables to distinguish, on one hand, two diagnoses, the semiological one and that of the organic disorder (or somatosis) and, on the other, because of the organic-clinical gap, two classifications. In addition, it enables to differentiate causality between "causes of the organic disorder" and "causes of the symptoms."

The causes of the organic disorder correspond, since Hippocrates' and Galen's time, to the external or procatartic cause and to the dispositive or proegumene cause, which, when combined, constitute the so-called joint or synectic cause, in fact the "Iesion," the somatosis or disorganization of the body. $\$ 10$ Conversely, the causes of symptoms are different. These causes or factors that "build" symptoms have a double relationship with somatosis, both directly, as symptoms of functional deficit, and indirectly, as symptoms-reactions. However, they are also essentially related to the physician/patient relationship, in which the symptoms are "built" in the dialogue that takes place in this anthropologic setting. Pain, as an example of a subjective symptom, as a patient's complaint, "becomes objective" in the body through a dialogue that depends both on the physician and on the patient.

\section{Semiological diagnosis and diagnosis of the organic disorder}

Semiological diagnosis consists of the analysis of the manifestations (symptoms and signs) of the condition, i.e., "perceiving" the disorder affecting the body. It is a technical activity in which manifestations are "observed" and in which this perceived totality (gestalt) is categorized according to the pathological knowledge of the physician. The semiological diagnosis is a continuous oscillation between what physicians perceive and what they know, between what they observe and the illness they know, it is seeing and knowing, in short, it is "knowing how to see" the illness. The symptoms of the illness are the result of functional deficits, but are also, and mainly, reactions of the organism in its attempt to recover the lost order. The complexity of the technical act of diagnosis is directly related to the organic-clinical gap, to this "distance" or "interval" that exists between somatosis and its manifestations. When this gap is very "broad," i.e., the "farthest" the symptoms are from the bodily disorder, the more difficulty it is for the physician to "see," "apprehend" the organic disorder "through" clinical manifestations.

On the other hand, the diagnosis of the organic disorder or somatosis requires working with a hypothesis about the reality of the organism. In order to know the nature of this vegetative organism, it was necessary to know about its different diseases. This was the way medicine shifted from knowing cadaver anatomy to being real knowledge on the "anatomy" of the living body.

Once vegetative disease was found as a natural reality, medicine progressively evolved, but in a very chaotic way. This situation determined, in the 16th century, Thomas Sydenham's proposal to diagnose and classify diseases only on the basis of their clinical manifestations, i.e., the "semiological forms," without arbitrary hypotheses about morbid processes. However, Sydenham himself could not be entirely faithful to this principle. As the reality of the body became understood through vegetative disease, this knowledge led to the development of different models of morbid process: initially anatomopathological, then physiopathological, and finally etiologic. ${ }^{11}$

In vegetative pathology, the organic-clinical gap is smaller, in the sense that functional manifestations "are very close" to the body. Moreover, due to this "closeness," although "semiological diagnosis" is always at the first place and is the way to "perceive" somatosis, in fact there was a trend to think directly of the organic process or somatosis. In practice and also in theorization, the symptoms and the semiological diagnosis are analyzed, but this analysis considers the diagnosis of the organic process. Whereupon, the semiological diagnosis of the vegetative condition is replaced with the diagnosis of somatosis and is also validated by this diagnosis. Hence, the character of vital reaction related to the disease process is blurred, and disease, which is the "living reaction" of the suffering patient and what the physician perceives, begins to be considered as an anatomic lesion, a laboratory finding, or a toxic, infectious, etc. factor. History has shown that this approach becomes acceptable in daily medicine. However, it should be criticized in a medicine that aims to be properly anthropological, i.e., in a medicine that understands disease not as an organic disorder but essentially as a way of life. ${ }^{9}$

\section{Double classification}

Every classification should be empirical and logical. ${ }^{12}$ Firstly, it should be empirical, i.e., based on the facts that one aims to classify, which implies integrating inductive and deductive processes to establish what allows to identify these facts. And secondly, it should be logical, i.e., emerge from ranking criteria that differentiate the

§ Which G.E. Berrios (from Cambridge, UK) designates as "biological signal"(cf. ref. 10). 
facts and, at the same time, enrich them by expanding the perception of reality. Generally speaking, purely logical classifications did not remain over time because they are not based on reality, and purely empirical classifications without ranking criteria are not useful because, although this approach make "the facts speak," they end up telling nothing.

Even though the two diagnoses of vegetative disease generate two classifications, one of semiological diagnosis and other of the diagnosis of somatosis, one actually works only with the classification of anatomopathological, physiopathological or etiological processes. It is worth considering whether it is possible to behave similarly in psychiatry, i.e., working with a single classification, with this being the classification of organic processes (e.g., genetic). Later on, we will provide a negative answer to this question.

As previously pointed out, the mental illness observed since the beginning of medicine consisted of some acute presentations recognized as more or less typical semiological forms. These forms, integrating a broad presentation that today could be named as "confusing confusion," highlighted two features of mental illnesses: firstly, they encompass psychic structures that are qualitatively different from normal psychic experiences, and secondly, they are clearly pathological. The grouping of these acute episodes, although inaccurate, represented indeed a vague acknowledgement of their unity. The term "confusing confusion" is not derogatory but expresses some essential features of acute mental presentations (mania, melancholia, and delirious episodes): their fairly sudden onset, alteration in consciousness, and their episodic or transient nature. ${ }^{* *}$

In acute mental episodes, "the mental feature," stereotyped and usually little individualized, reflects the existence of a small organic-clinical gap. For the same reason, in vegetative disease praxis, there is a trend to identify the semiological diagnosis (e.g., mental confusion) with the diagnosis of the organic process and according to the determining causative factor (metabolic, toxic, infectious encephalopathy).

However, as shown later in this paper, even in these "monotonous and organic" acute manifestations in which the organic-clinical gap is smaller, it is not possible to replace the semiological diagnosis with that of the somatic disorder. This impossibility is explained when psychiatry is understood exactly what it is: a specifically mental medical knowledge, and thus complex. Even when the complexity of acute mental illness is not that of personal ideo-affective process of chronic mental illness.
It is worth pointing out that, during this long period preceding the discovery of mental illness in the 17th century, psychological reflections of philosophical nature arose. In the high Middle Ages (13th century), philosophers, reflecting inductively, provided rational psychological and partly empirical analyses. For instance, Saint Thomas Aquinas, considering the many factors of "involuntariness" of the voluntary act, presented a primitive form of psychopathology, ${ }^{13}$ although the mental data used were those which subsequently will be named "psychology of folklore."

\section{Progressive apprehension of the "mental feature" of chronic mental illness}

\section{Discoveryofmentalillnessandinstitutionalization of psychiatry (17th-18th centuries)}

After the 17th century, chronic manifestations were added to the recognized acute manifestations, and with them medicine incorporated those pathological mental forms in which "the mental feature" appears determined from "within" the person.

Thus, besides the two features of mental illness, i.e., being mental variations qualitative different from normal mental variations and being pathological, a third feature was added: the fact that manifestations appear determined by "internal forces," more "endogenous" in the sense that they are essentially related to the biopsychological constitution of the individual.

Psychiatry was born in the "complex" situation of contrasts that marked Renaissance (L. Vives, Erasmus of Rotterdam, Thomas Moro, among others). By oscillating between setting men's imagination free ${ }^{14}$ and restricting their freedom (persecution of heretics and witches, established by the Malleus Maleficarum, ${ }^{15}$ etc.), mental illness evidenced itself in its reality. Due to the confluence of several historical and cultural factors, facing the acknowledgment of man as a "creator of values" and thus free and responsible, it became evident that some men were pathologically diminished in this properly human ability. ${ }^{16}$ Among other authors, Paolo Zacchias and John Weyer stated that these mental variations were not a consequence of benign or malignant supernatural actions, but were rather natural phenomena. The psychism discovered by mental illnesses became evident as a vulnerable reality, i.e., as a body order different from that of the vegetative organism. Within the order of the organism, it was possible to perceive the reality of the another organism, the "psychic body."

\footnotetext{
** This way of inaccurately conceptualizing the multiplicity of acute episodes is still used by non-psychiatrist physicians, including neurologists, whose diagnostic interest is differentiating this acute semiology from "comatose diseases" (urgency) and from dementia syndromes (definite disability).
} 
This late discovery of mental illness, 22 centuries after the birth of medicine, shows that it was not easy to recognize and accept that some mental variations are pathological. The dualistic thinking of men that makes it difficult to apprehend a reality that is "illness" and "mental" at the same time was and is expressed by the cultural trend for not perceiving and even denying the difference between mental illness and health. Additionally, unlike the "deviations from the type," which are easy to observe in vegetative diseases, it is not easy to establish the pathological nature of an experience or a behavior, since the subject is the center of endless variations.

Psychiatry, working with this different mental "clinical mass," which was progressively identified, developed, on one hand, as a theoretical and practical science of the relationships between biological and mental features ("physical and moral features" referred to in the context of nervous physiology (Cabanis) ${ }^{17}$ and, on the other, as a practical knowledge that should respond to the organizational and legal problems posed by the existence of mentally-ill patients. ${ }^{18}$

Identification of mental illness as the specific subject of psychiatry (from the 19th century to the present day)

During the 19th century, chronic mental disorders were initially studied with the idea that there was only one mental illness, "alienation," and that its different manifestations were the expression of the different evolutionary moments of this "single psychosis." In the second half of the century, psychiatry began to consider mental manifestations as multiple diseases. On both moments, the study of mental illnesses (Pinel, ${ }^{19}$ Esquirol, ${ }^{20}$ etc.), which were considered organic disorders, due to the lack of concrete knowledge about these processes, focused on the semiological study of "the mental feature."

This analysis of "the mental feature" of mental illnesses was performed according to the context of the medical thinking of the time. In the strictly mental sense, these analyses have provided a specific semiology, with a detailed description of the symptoms, but, as there was no accurate idea of what a "symptom" was in psychiatry yet, analyses represented only, as stated by E. Minkowski, a "pathological reading of the psychological feature."21 Based on a picture of what was psychologically normal, pathological manifestations, e.g., of the mood, when compared to this picture, were called "hyperthymia," "hypothymia," or "dysthymia." And, although the manifestations of chronic mental illness evidenced the existence of an organic-clinical gap that the mental activity of the patients "filled," they disappeared as subjects, because their experiences and mental processes were considered from the point of view of vegetative disease. A point of view that -with some degree of violence- could be applied to acute mental illness but not to chronic mental illness.

When analyzing the status of psychology in the 19th century, G. Lanteri-Laura ${ }^{22}$ points out that, during that century, the scientific developments revealed an intrinsic difficulty of mental illness. Due the unitary nature of mental life, some people tend to think of mental illness as a "unitary psychosis," and other people recognize the existence of different mental illnesses. This dual way of thinking the concrete existence of mental illness represents a particular aspect of the phenomenon, and the predominant choice is usually related to the aspect of mental life most emphasized by who classifies it. When normal mental life is perceived and considered as a unit and organic aspects are minimized, there is a trend to consider mental illness only as "one illness" or, which occurs more often, as being constituted by some very comprehensive syndromes (e.g., syndromes like "somatic symptom disorder," which is currently proposed in the DSM-5 project). This perception of psychic unity corresponds to the primary experience the practical psychiatrist has when capturing the nature of totality implied by the mentally-ill subject. In turn, when mental life is considered as an integration of evolutionary functions of an organic development, there is a trend for advocating for the existence of several mental illnesses. This perception corresponds to the experience of the psychiatrist who captures the disintegrative procedural effects of the psychic unity in the different syndromes.

The classification of mental illness should solve this tension, and this was achieved according to the prevailing trend, either "grouping" (the "lumpers") or "separating" (the "splitters"), which explains the flowing and reflowing between very broad and very limited diagnostic categories. The practical solution to this problem is acknowledging that, due to its organicity, regressive mental life presents itself in several forms of mental illness, and, at the same time, due to the unitary nature of psychism, not multiplying unnecessarily the number of pathological forms.

Within this "unity / multiplicity" tension, mental illness continued to be classified, just like it had been happening since the 17 th century, based on different criteria: according to symptoms, according to its evolution, and usually merging etiological assumptions.

From the end of the 19th century to the mid-20th century, psychiatry made an essential discovery: it achieved to comprehend what is the reality of "the mental feature" that is disorganized in mental illness. This conceptual revolution developed according to two 
orientations and based on different clinical materials: the psychiatric clinical orientation made it in psychosis and the psychoanalytic orientation in neurosis.

The clinical orientation, studying the psychic manifestations as an expression of a somatosis, has recognized, in mental organization, the types of deficits determined by organic processes. From these clinical developments, focused on the study of chronic psychosis, four time points should be highlighted:

a) Firstly, E. Kraepelin ${ }^{23,24}$ argued that heterogeneous patients from the point of view of their manifestations (patients with dementia praecox as described by Morel, hebephrenic as described by Hecker, catatonic as described by Kahlbaum, and most of chronic delirious patients) represented one illness: Dementia Praecox. Although Kraepelin sensed the reality of a deficit in the psychic organization (which he inaccurately expressed as "disorders in essential psychic functions" or "relaxation of the affective forces that maintain the coherence of the psychism"), his approach was still closely related to the vegetative model of thinking the illness. The unity that Kraepelin provided to these manifestations of different semiology was stating that all of them were the expression of a process of somatic disorganization, clinical forms of the same organic process.

b) E. Bleuler ${ }^{25}$ took a step further: he aimed to capture the unity of the different forms of early dementia, not in the fact that they were manifestations of the same somatic process, but rather in the own mental structure. Thus, he found that the unity of this symptomatic variability was what constituted a special psychic state. These different manifestations were not unified by an organic process (the Kraepelinian somatosis of early dementia) but rather by a unity of mental process. Hence the absolute need of changing the name (these patients, stated Bleuler, "are not mentally ill because they are schizophrenic"), since what characterizes these manifestations is not an organic process that points out a terminal defect but rather the fact of presenting themselves as a special type of mental activity in which the clinical forms of this pathological structure are secondary. This Bleulerian development meant several essential aspects. Firstly, it represented a clinical analysis of the psychism as such, i.e., in its "own thickness" (thus the inclusion of Freudian concepts in his work) and, consequently, psychiatry became psychopathological. Secondly, this psychic analysis of the pathological feature determined that Bleuler talked about essential symptoms (clivage or Spaltung, autism, dereistic thinking, etc.) and accessory symptoms (e.g., acute syndromes), the first being the expression of the infrastructural disorder determined by somatosis, and the second the facultative manifestations of the mental reaction to disorganization. With this distinction, Bleuler recognized the organic-clinical gap that exists in mental illness between somatosis and its clinical expression. Thirdly, with the subtitle of his book: "group of schizophrenias," he pointed out that the unity and diversity of schizophrenia as a mental process could be the expression of different somatoses.

c) The third step, opened by the Bleulerian conception, was the progressive use of a semiological phenomenological-structural method. ${ }^{26-28}$ Thus, it was possible to capture, in the variety and in the atypia of manifestations, the typical feature of each of the different psychic deficits. With this method, a "psychological reading of the pathological reality" was achieved, which enabled to describe the psychopathological structures (which make "one" symptom to be the manifestation of "such" structure) and also to classify them according to strictly psychological criteria.

d) The fourth movement was done using the phenomenological method and consisted of facing and solving the difficulties implied in acute mental illness. Acute delirious manifestations, although being known since the birth of medicine, were not accurately conceptualized nor coherently integrated with other psychiatric manifestations. Considered by Kraepelin as a second-order remainder of the "actual insanity," they were in turn valued by Bleuler as a problem to be solved in the future and were addressed by Henry Ey as the central focus of his work. He dedicated the third volume of his Études Psychiatriques ${ }^{29}$ to the research and the discovery of the unity of the pathology of the field of consciousness. Breaking with the tradition of basing psychopathological studies on chronic pathology, Ey described the array of acute disorders (mania, depression, acute delirious psychosis, and mental confusion) as "levels of destructuration of the field of consciousness."

Three features that accurately but vaguely identify "mental illnesses" were previously pointed out: being different from normal psychic variations, being the expression of somatic disorders and also being the manifestation of internal ("endogenous") events. The above-mentioned clinical investigations were able to specify these three features of mental illnesses. 1) Their pathological nature has been objectified by the rupture in inter-subjective communication and by the understanding of psychic manifestations. The somatic disorder objectified by the phenomenological method evidenced the existence of a specifically mental body order. 2) The analysis of the "mental feature" reveals its categorical nature, since the qualitative difference of the somatic process also expresses itself qualitatively in the psychopathological structuration 3) whose manifestations can be explained when procedural disorder is added to 
the psychic construction of the symptoms or psychic pathogenesis by which mental illnesses are "mental."

The above-mentioned scientific developments, working on the nature of the "endogenous feature," have made psychiatry a medical knowledge that is properly psychological, psychopathological, and in which the "mental feature" as the subject of its knowledge and praxis is the disorganization of the "bodily-mental" level. An infrastructural mental reality that, when organized, enables the facultative psychic movements of normal life, and, when disorganized by somatosis, determines the psychic construction of the syndromes that are clinically diagnosed as forms of regressive mental life.

These syndromes, which represent the primary objective of psychiatry, are characterized: a) by being evolutionary levels, with each of them, due to the unitary nature of the psychism, not excluding the overand underlying levels ( "spectral" nature of semiological diagnoses) ${ }^{30}$; b) by being syndromes that express somatosis and consequently, similar to the latter, are qualitatively different from normal psychic manifestations (they are categorical and require a specific method to be known); c) by being syndromes that are "useful" from the clinical point of view, due to a certain degree of evolutionary and prognostic homogeneity (recovery, worsening, social disability, possibilities of treatment, etc.) ${ }^{31}$; d) by being syndromes that are "naturally" organized according to two subgenera of mental illness: acute mental illness, whose episodes are experienced as "accidents," and chronic mental illness, in which disorders "blend" with the person; e) by being syndromes that, even though evidencing the organic disorder, are valid by themselves, and therefore should not and cannot be replaced with the diagnosis of the organic disorder.

Through the phenomenological clinical approach, psychiatry has found the "thickness" of mental life and consequently the amplitude of the organic-clinical gap shown by mental illness. The reality of this gap, which is fulfilled by psychic activity, determines that in mental pathology-differently from what happens in vegetative disease-it is necessary to work with two diagnosis and therefore with two classifications. It means that in mental pathology there is a demand to organize (classify) separately semiological diagnoses and the diagnoses of the generating organic processes (as an example of this need of two diagnosis and thus two classifications, one can consider evolution with regard to genetic causality in psychiatry). ${ }^{32}$

In summary, during the 70 years, from 1890 to 1960 , psychiatry achieved an identity for its theoretical and practical subject, perceiving the existence of an infrastructural psychic order (an organized somatopsychic "thickness"), through facultative mental manifestations.
The psychoanalytical orientation, both Freudian and Jungian, by finding the forms of drive organization of the diseased mental life, allowed to understand the laws that build the symptoms. The fact that patients are the "unconscious agents" of their disorders was naturally integrated into the evolution of psychiatry (as Bleuler did in his work) and psychoanalysis became an important part of psychological investigation in psychiatry and one of the forms of treatment. However, when psychoanalysis became hegemonic, it ended up being considered, by physicians and also by the "men of culture," as if it was psychiatry. ${ }^{33}$

This psychoanalytical psychiatry, based on unconscious drive and on the idea of conflict, was moving its praxis towards the mental health field in which both concepts are widely accepted. This meant a growing lack of interest in diagnosis, i.e., in the perception of the structural differences between health and illness. Since psychiatry became progressively occupied with people with existential conflicts but who were not properly mentally-ill and lost its interest in diagnosis, the ability of diagnosing was lost.

On the other hand, psychoanalysis, due to its focus on how symptoms were built, blurred the concept of mental illness that was so hardly achieved by clinical evolution, and, because it worked with the hypothesis of psychic causality, divided the psychiatric field into organic genetic and psychogenic mental illness.

\section{Current diagnosis and classification systems (DSM-IV, ${ }^{34}$ ICD-10, ${ }^{35}$ and DSM-5 project $^{36}$ )}

The above-mentioned state of affairs, together with the emergence of efficient therapies and thus of the possibility of differential treatment plans, determined a crisis that motivated an interest in diagnosis and classification. This reaction "in favor of diagnosis," initiated and conducted by an "invisible college," ${ }^{137}$ was crystallized in 1980 with the DSM-III. ${ }^{38}$

This guidebook and the changes it has undergone since 1980 have positive and negative aspects. ${ }^{39}$ Among the first ones, it should be pointed out: a) the fact that they grounded the need for a psychiatric diagnosis; b) the need for distinguishing, in terms of concept and practice, the diagnosis of psychic syndromes (psychopathological) and that of diseases processes and causes; c) the use of diagnostic criteria and rules (algorithmic) that enable the apprehension of the phenomena in their "psychic reality," and that increase the agreement between technicians; d) the proposal of abandoning the organic / psychic dichotomy, and e) the multiaxial codification 
that, although being still mostly heteroclite, points out the acknowledgment of the need for two classifications. Among the questionable aspects, it is worth highlighting: a) the lack of a critical analysis regarding the use of "operational symptom"40; b) the fact that semiology and etiology are still mixed in axis I; and c) the fact that, although some changes in axis II cover more than the classic character disorders and make it close to Ey's concept of "disorder in personality development," this axis still has no clear psychopathological robustness.

The reaction in favor of diagnosis and classification that took place in psychiatry since the 1970's has vitalized the evolution of psychiatry. However, the successive changes to DSM-III (DSM-III-R, DSM-IV, DSM-IV-TR, and the current DSM-5) seem to indicate that something is missing in this reaction in order to achieve a more stable result. Among these deficiencies, maybe the most relevant is the lack of an accurate identity for mental illness, adding other difficulties to the highlighted intrinsic ones, which constitute "false problems," because they were already solved but remain implicit by erroneous hypotheses.

The first false problem is generated by the questioning whether the diagnoses should be categorical or dimensional. As previously seen, the qualitative difference of somatosis is necessarily expressed in manifestations, and thus psychopathological structures should only be categorical, qualitatively different from healthy mental variations. Stating that the semiological diagnosis is not dimensional does not mean that one should not take into account essential dimensions for the evaluation of a concrete patient. However, insisting that diagnosis can be dimensional is a consequence of not operating with the specific semiological method and continuing to project the dimensional experiences provided by introspection, similar to what was done in the 19th century. In other words, it is the result of neither acknowledging nor integrating the change in the semiological method that is specific of psychiatry, ${ }^{41}$ and is thus maintaining oneself "outside" the reality of mental illness.

The second false problem, which is very linked to the psychoanalytical hypothesis, is the traditional question of whether the causality of mental illness is organic or psychic. Since this pathology is a "pathology of the psychic reactivity, ${ }^{\prime 42}$ i.e., a disorganization of the mental infrastructure of the psychic organism, the question can be answered only by distinguishing "organic causes of somatosis" (mental illness is a disorder of the psychic reactivity), and "causes of the symptoms" (causality that is always psychic and thus sociocultural).
The third false problem consists of stating that: "semiological diagnoses should be validated by somatic diagnoses." This statement can only be based on the capture of the gap that exists in mental pathology between organic process and clinical manifestations. This gap, fulfilled by psychic activity, differently from what happens in a vegetative disease, determines that the semiological diagnosis cannot be replaced with the diagnosis of somatosis (anatomopathological, physiopathological or etiologic). This false problem is today related to the "bottom-up" scheme of most of the current neurobiology. ${ }^{+\dagger}$

These difficulties, linked to the "mental" nature of mental illness, are now "enhanced" by other scientific developments: 1) the reductive method of neurobiology, which, although being ambiguously presented by some authors, ${ }^{43}$ ends up representing a new "ideology," as psychoanalysis did before; 2 ) the fact that psychoanalysis returns to psychiatry without criticizing the negative aspects of its hypothesis regarding diagnosis; 3 ) the entry of Anglo-Saxon analytic philosophers in the psychopathological field, ${ }^{44,45}$ who, although appropriately questioning the "securities" of the reductive models, tend to replace empirical psychiatric knowledge with a deductive knowledge, due to their own methodology ${ }^{46}$; 4) the fact that psychiatrists find themselves with the problem of having to balance their concrete clinical duties with others goals that, due to their economic weight, require to be prioritized (pharmacological investigations, organization of healthcare and prevention services, health insurance costs, "malpractice" demands, etc.).

\section{Need for a psychiatric working hypothesis like that of Henry Ey}

The research outlined in this article shows the need of working with a psychiatric hypothesis that, to be valid, should comply with three rules. ${ }^{47}$ Firstly, it should be empirical, that is, codify the observed clinical facts and the results of the experiment (i.e., be the result of a long clinical experience). Secondly, it should be logical, that is, constitute a coherent system regarding the structure of the psychic being as well as the causality of morbid phenomena (i.e., be the result of a reflection on the relationships between body and mind). Thirdly, it should be heuristic, that is, involve practical corollaries, which should take into account the practical problems that are part of the definition of their subject, i.e., be practically efficient, making it easier for clinicians to respond to the different situations they may face.

\footnotetext{
${ }^{++}$Scheme that leads one to think, for example, that it is also possible to use kappa index values in psychiatry (which, in vegetative pathology, are related to genetic, biomarkers, EEGs, etc.).
} 
This article was developed following exactly the principles of a hypothesis that comply with these three features: the psychiatric working hypothesis proposed by Henry Ey. ${ }^{48-51}$ The core of this hypothesis is that it responds to the two aspects of reality that "mental illness" is, being an organic disorder and being of "mental" expression. ${ }^{\neq \neq}$A reality that should be considered by psychiatry as it is: a somatopsychic reality, which, in order to be conceived, requires to go against the natural Cartesian way of thinking of man that states that if something is a disease cannot be mental and that if something is mental cannot be a disease. Ey points out that the prodromes of his organic-dynamic conception of psychiatry appear repeatedly in the psychiatric studies of several authors (from Maine de Biran to Moreau, Ribot, Jackson, Janet, Freud, Bleuler, etc.), which sometimes constitute the axis of its development.

Four proposals organize this working hypothesis. The first one (or psychological thesis) refers to the organization of the psychic being or mental organism in which mental illness is virtual. Virtuality that should be understood in two senses. On one hand, virtual meaning the power of falling mentally ill ("lethal latency" as stated by Bichat), and requiring a morbid process to become actual. On the other, virtual in the sense of "driving contents" that, when "controlled," i.e., integrated, comply with their function in normal psychic structures and, when "uncontained," build the symptoms of each type of psychopathological structure. The second thesis asserts that mental illness is essentially regressive and that this negative nature that supports it requires a phenomenological analysis, which is what evidences the rupture of the relationships of understanding and what allows to understand mental illness as a destructuration of the system that organizes reality. Thirdly, Ey states that mental illnesses, due to their structure and evolution, are typical forms of the levels of dissolution of the psychic organism, which he names as "psychic body." This thesis is what made Ey's contribution relevant, since the phenomenological analysis of mental pathology has enabled him to find that the psychic organism is the articulation of two dimensions: the current awareness field (the "field of consciousness") and the dynamic personality development (the "Self"), and that this dual nature of mental life, which is not perceived in health (when it disappears, due to its integration,), is revealed, in turn, by mental illness. A dual nature that constitutes the natural order to classify the different forms of regressive mental life: as acute pathology (the crises as destructurations of the current awareness field) and as chronic diseases (as "pathologic balances" of the personality development, when the relationships of the Self and the Other, i.e., the "ways of being the Other that the Self should not be" are inverted or merged). In the fourth thesis, Ey asserts that mental illnesses depend on organic processes in the sense that their proper causality is the disorganization of the psychic being. A disorganization that, in the form of a "third person process," disorganizes the unity and the power of the "first-person subject," which always builds the symptoms (psychic pathogeny) in the organic-clinical gap that exists between somatosis and psychic manifestations.

The working hypothesis schematically presented appears as a model that, responding to the clinical facts, constitutes a theoretical and practical background very useful in the current moment of confusion experienced by psychiatry.

This hypothesis enables: 1) to distinguish organic disorder and clinical manifestations, and thus to operate with two diagnoses and two classifications; 2) to recognize, in face of the trend to uniqueness, the existence of a nonexcessive number of "psychopathological structures"; 3 ) to understand that these psychopathological structures are qualitatively different from normal psychic variations (which are categorical and not dimensional); 4) to recognize that such forms of regressive mental life are naturally organized according to the two structures that, when articulated, constitute the mental organism (the field of consciousness and personality development); 5) to state that semiologic diagnoses are validated by structural analysis and not by the diagnoses of the organic processes; 6) to differentiate between "causes of organic disorder" and "causes of the construction of mental symptoms" and thus to assert that every mental illness is "organogenic and "psychogenic" ("exogenous" and "endogenous"); 7) to operate with two classifications, which allows one to freely and creatively move in the different objectives that should be achieved in the fields of psychiatry and "mental health."

\section{Conclusions}

1) Throughout the evolution of diagnosis and classification in mental pathology, two types of difficulties

\footnotetext{
\#¥ This disorder is the result of a generating process, i.e., a procedural disorganization of the body, of the 'psychic body'. The neo-Jacksonian model of Henry Ey, achieved through the phenomenological analysis of mental pathology, expresses that this disorganization: (a) is the dissolution of the life of relationship, i.e., of the integration function of the nervous system (different from the neurological dissolutions of integrated and focusable functions according to the concept of localization, non-applicable to mental diseases) and (b) is a deficitary, but essentially reactive, dissolution, a real and living psychic construction of the subject.
} 
that are related to "the mental feature" of mental illnesses have been stressed.

Some of these difficulties have been solved once psychiatry, abandoning the initial medical scheme that is valid for the pathology of vegetative life functions, has turned into a specifically mental model, in which "the mental feature" refers not to the manifested symptoms but rather to what they show: the reality of an infrastructural "mental" organization. A reality that is only revealed by the phenomenological analysis of the facultative mental movements of the subject. This "psychic thickness" that fulfills the organic-clinical gap and has a "somatopsychic" nature mediates between somatic disorganization, which is determined by the morbid process, and the facultative manifestations built psychically. The phenomenological analysis of the different forms of mental pathology enabled Henry Ey to find the dual structure of the conscious being: as the current field of consciousness and as the development of the personality.

These difficulties, originated in the nature of "the mental feature" of mental illness, will always be present in the psychiatric reflection. The first difficulty is motivated by the fact that mental illness is a real phenomenon and not a mythical one, and that its manifestations are qualitatively different from the endless healthy mental variations. The second, by the fact that, although mental life is unitary, when it becomes disorganized, this happens through several diseases. The third, by the fact that, in order to answer coherently to the several questions raised by practice, it is necessary to recognize the need of working with two diagnoses, one semiological and the other related to the organic process, and also with two classifications that do not merge both diagnoses.

Other difficulties were solved as psychiatry evolved, but are reasserted because they do not incorporate the achieved solutions. These methodological difficulties are: first, insisting that the semiological diagnosis should be dimensional; second, reasserting that the validity of the semiological diagnosis should be established by knowing the diagnoses of the "somatosis"; and third, stating that psychic factors, besides building the symptoms, can also cause the organic disorder.

In fact, these difficulties constitute "false problems," since its proposal, not corresponding to the reality of mental pathology, has no other solutions than those achieved by psychiatry.

2) The highlighted difficulties, which are intrinsic to the reality of mental pathology, and the abovementioned false problems that originate from partial hypotheses, show the need for psychiatry to work with a hypothesis that is based on facts, coherent, learnable and teachable, and that responds to the needs of the clinician. The working hypothesis organized by Henry Ey (the "organic-dynamic" model) responds to these demands. On one hand, it is a solid theoretical base for dealing with psychiatric diagnosis and its classification. On the other, it constitutes a very useful framework for practical psychiatrists who, in their work, need to create "new and adequate" answers to the suffering of their patients, answers that they cannot find in "therapeutic guidelines."

\section{References}

1. Ey $\mathrm{H}$. Existence de la psychiatrie (réflexions sur le problème de I"intégration des Hôpitaux psychiatriques dans les Hôpitaux généraux). Presse Med. 1959;67(suppl. 33):257-8.

2. Ey H. Étude no 20: la classification des maladies mentales et le problème des psychoses aiguës. Paris: Desclée de Brouwer; 1954. v. III. [trad. española: Buenos Aires: Polemos; 2008. v. II, p. 13-50].

3. Essen-Möller E. On classification of mental disorders. Acta Psychiatr Scand. 1961;37:119-26.

4. Stengel E. Classification of mental disorders. Bull World Health Organ. 1959;21:601-63.

5. Pichot P. editor. DSM-III et psychiatrie française. Paris: Masson; 1984.

6. Sadler JZ, Wiggins OP, Schwartz MA, editors. Philosophical perspectives on psychiatric diagnostic classification. Baltimore: The Johns Hopkins University Press; 1994.

7. Regier DA, Narrow WE, Kuhl EA, Kupfer DJ, editors. The conceptual evolution of DSM-5. Washington: American Psychiatric Publ.; 2011.

8. Blankenburg W. La psicopatología como ciencia básica de la psiquiatría. Rev Chil Neuropsiquiatr. 1983;21:177-88.

9. Lain Entralgo P. Historia de la medicina. Barcelona: Salvat; 1981.

10. Berrios GE. Hacia una nueva epistemología de la psiquiatría. Buenos Aires: Polemos; 2011.

11. Lain Entralgo P. El diagnóstico médico. Historia y teoría. Barcelona: Salvat; 1982.

12. Ey $H$. Nature et classification des maladies mentales. Esquisse d"une histoire naturelle de la folie. (Suecia, 1963, no publicado, Archives Municipales de Perpignan, France).

13. Krapf E. Tomás de Aquino y la psicopatología. Buenos Aires: Index; 1943.

14. Erasmo de Rotterdam. Elogio de la locura. Madrid: EspasaCalpe; 1972.

15. Kramer H, Sprenger J. Malleus Maleficarum (El martillo de las brujas). Traducción española de Miguel Jiménez Monteserin. Valladolid: Maxtor; 2010.

16. Ey $\mathrm{H}$. Introduction à la psychiatrie. Histoire de la psychiatrie. Encyclopédie Médico-Chirurgicale, Psychiatrie (1), 37005 A10, A20, A30; 1955.

17. Cabanis JG. Rapports du physique et du moral de I"homme. 8th ed. Paris: Baillière; 1844

18. Ey $H$. Étude no 3: le développement "mecaniciste" de la psychiatrie à I"abri du dualisme "cartésien". Paris: Desclée de Brouwer; 1952. v. I. [trad. española: Buenos Aires: Polemos; 2008. v. I, p. 49-65].

19. Pinel P. Traité Médico-Philosophique sur I"aliénation mentale. 2nd ed. Paris: Seuil; 2005.

20. Esquirol JE. Tratado completo de las enajenaciones mentales. Madrid: Imprenta Colegio Sordo-Mudos; 1847.

21. Zilboorg G, Henry GW. La era de los sistemas. In: Historia de la psicología médica. Buenos Aires: Hachette; 1945. p. 434-552.

22. Lanteri-Laura G. Essai sur les paradigmes de la psychiatrie moderne. Paris: du Temps; 1998.

23. Kraepelin E. Trattato di psichiatria. II: Psichiatria Speciale. 7th ed. Milano: Vallardi; 1906. 
24. Kraepelin E. Dementia Praecox and paraphrenia. New York: Krieger; 1919. (reprint 1971).

25. Bleuler E. Dementia Praecox or the Group of schizophrenias (translated by Joseph Zinkin). New York: International Universities Press; 1950. [trad. al español, Buenos Aires: Polemos; 2011].

26. Minkowski E. Traité de psychopathologie. Paris: Presses Universitaires de France; 1966.

27. Spiegelberg $H$. Phenomenology in psychology and psychiatry. Evanston: Northwestern University Press; 1972.

28. Rollo M, Angel E, Ellenberger HF. Existencia. Nueva dimensión en psiquiatría y psicología. Madrid: Gredos; 1977.

29. Ey H. Etudes psychiatriques, t.III. Paris: Desclée de Brouwer; 1954. [trad. española vol II, Buenos Aires: Polemos; 2008].

30. Casarotti H. Espectros en psiquiatría desde la perspectiva órgano-dinámica de Henri Ey. Vertex. 2007;18(supl 3):1723.

31. Kendell R, Jablensky A. Distinguishing between the validity and utility of psychiatric diagnoses. Am J Psychiatry. 2003;160:4-12.

32. Casarotti H. Semiología psiquiátrica y endofenotipos. Rev Soc Psiq Biol Urug. 2007:3-12.

33. Casarotti H. Relaciones entre psiquiatría y psicoanálisis (desde finales del siglo XIX hasta el momento actual). Rev Psiquiatr Uruguay. 2010:74:103-15.

34. American Psychiatric Association. Diagnostic and Statistical Manual of Mental Disorders - 4th edition (DSM-IV). Washington: APA; 1994.

35. Décima revisión de la Clasificación Internacional de las Enfermedades (CIE-10). Trastornos mentales y del comportamiento (descripciones clínicas y pautas para el diagnóstico. Madrid: Forma; 1992.

36. American Psychiatric Association. DSM-5 development. http://www.dsm5.org

37. Klerman GL. The significance of DSM-III in American psychiatry. In: Pichot $P$, editor. DSM-III et psychiatrie française. Paris: Masson; 1985. p. 19-39.

38. American Psychiatric Association. Diagnostic and Statistical Manual of Mental Disorders - 3rd edition (DSM-III). Washington: APA; 1980.

39. Casarotti H. La aportación de H. Ey al diagnóstico de las psicosis delirantes. In: Ey H. Estudio sobre los delirios, 1950. Madrid: Triacastella; 1998.
40. Parnas J, Sass LA. Varieties of "phenomenology": on description, understanding and explanation in psychiatry. In: Kendler KS, Parnas J, editors. Philosophical issues in psychiatry. Explanation, phenomenology and nosology. Baltimore: The Johns Hopkins University Press; 2008. p. 239-85.

41. Flavell JH. La psicología evolutiva de Jean Piaget. Buenos Aires: Paidós; 1968.

42. Ey H. La notion de "réaction" en psychopathologie (Essai critique). Confront Psychiatr. 1974;12:43-62.

43. Kandel ER. A new intellectual framework for psychiatry. Am J Psychiatry. 1998:155:457-69.

44. Graham G, Stephens GL. Philosophical psychopathology. Massachusetts: MIT Press; 1994

45. Radden J, editor. The philosophy of Psychiatry. New York: Oxford University Press; 2004.

46. Piaget J. Sabiduría e ilusiones de la filosofía. Barcelona: Flamma; 1970.

47. Ey $\mathrm{H}$. Outline of an organo-dynamic conception of the structure, nosography, and pathogenesis of mental diseases. In: Natanson $M$, editor. Psychiatry and philosophy. Berlin: Springer; 1969. p. 111-61.

48. Ey H, Rouart J. Essai d'application des principes de Jackson à une conception dynamique de la neuropsychiatrie. Encéphale. 1936;31(1):313-56, 31(2):30-60, 96-123.

49. Ey $H$. Principes d'une conception organo-dynamiste de la psychiatrie. In: Ey H. Etudes psychiatriques, t.I, 7:157-86. Paris: Desclée de Brouwer; 1952.

50. Ey $H$. Le modèle organo-dynamique. In: Ey $H$. Traité des hallucinations, VIIème partie: 1069-1342. Paris: Masson; 1973 [trad al español, Buenos Aires: Polemos; 20 tomo, p. 1153-454].

51. Ey H. Des idées de Jackson à un modèle organo-dynamique en psychiatrie. Toulouse: Privat; 1975.

\section{Correspondence}

Dr. Humberto L. Casarotti

Presidente Berro, 2531

11600 - Montevideo - Uruguay

E-mail: humberto.casarotti@gmail.com 